\title{
Modulating proximal cell signaling by targeting Btk ameliorates humoral autoimmunity and end- organ disease in murine lupus
}

\author{
Jack Hutcheson ${ }^{1}$, Kamala Vanarsa', Anna Bashmakov', Simer Grewal', Deena Sajitharan', Betty Y Chang ${ }^{2}$, \\ Joseph J Buggy², Xin J Zhou ${ }^{3}$, Yong Du', Anne B Satterthwaite ${ }^{1}$ and Chandra Mohan ${ }^{1 *}$
}

\begin{abstract}
Introduction: Systemic lupus erythematosus is a chronic autoimmune disease characterized by an abundance of autoantibodies against nuclear antigens. Bruton's tyrosine kinase (Btk) is a proximal transducer of the BCR signal that allows for B-cell activation and differentiation. Recently, selective inhibition of Btk by PCl-32765 has shown promise in limiting activity of multiple cells types in various models of cancer and autoimmunity. The aim of this study was to determine the effect of Btk inhibition by PCI-32765 on the development of lupus in lupus-prone B6. Sle1 and B6.Sle1.Sle3 mice.
\end{abstract}

Methods: B6.Sle1 or B6.Sle1.Sle3 mice received drinking water containing either the Btk inhibitor $\mathrm{PCl} 32765$ or vehicle for 56 days. Following treatment, mice were examined for clinical and pathological characteristics of lupus. The effect of $\mathrm{PCl}-32765$ on specific cell types was also investigated.

Results: In this study, we report that Btk inhibition dampens humoral autoimmunity in B6.Sle1 monocongenic mice. Moreover, in B6.Sle1.Sle3 bicongenic mice that are prone to severe lupus, Btk inhibition also dampens humoral and cellular autoimmunity, as well as lupus nephritis.

Conclusions: These findings suggest that partial crippling of cell signaling in B cells and antigen presenting cells (APCs) may be a viable alternative to total depletion of these cells as a therapeutic modality for lupus.

\section{Introduction}

Systemic lupus erythematosus (SLE) is a systemic autoimmune disease characterized by the presence of autoantibodies, particularly against nuclear self-antigens. The recognition of these antigens by their cognate antibodies and the resultant deposition of immune complexes leads to the development of a chronic inflammatory state, which can have devastating effects on multiple end organ targets including the kidneys, the cardiovascular system, the skin, and the central nervous system. While the exact etiology of SLE is unclear, it is well established that SLE is a polygenic disorder with multiple dysregulated hematopoietic cell types contributing to the full-fledged disease state. To this end, it has been challenging to devise

\footnotetext{
* Correspondence: chandra.mohan@utsouthwestern.edu

${ }^{1}$ University of Texas Southwestern Medical Center, Department of Internal Medicine, Division of Rheumatic Diseases, 5323 Harry Hines Blvd., Dallas, TX 75390-8884, USA

Full list of author information is available at the end of the article
}

effective therapies for SLE given that multiple cellular and molecular checkpoints go awry in lupus. Bruton's tyrosine kinase (Btk) is intriguing as a potential therapeutic target in SLE given its proximal location in the B cell receptor (BCR) signaling cascade, as well as its previously described role in multiple myeloid cell types [1-5].

Many studies have focused on the role of B cells in lupus, and B cells have historically been a main target for SLE therapeutic interventions. Despite numerous studies and approaches to this problem, the goal of limiting the $\mathrm{B}$ cell response in SLE remains elusive [6]. Near-total elimination of $\mathrm{B}$ cells is problematic because it is becoming increasingly evident that $B$ cells serve a number of other functions besides antibody (and autoantibody) production. These critical processes include $\mathrm{T}$ cell survival and anergy, promotion of regulatory $\mathrm{T}$ cells, and synthesis of antiinflammatory cytokines, amongst others. Therefore, a

\section{Ciomed Central}


more nuanced approach focused on dampening the B cell response may prove to be more beneficial in SLE.

Since B cell activation is achieved through BCR signaling, members of the BCR signaling cascade are of particular interest for study with regards to SLE. Btk has been a prime target due to its proximal location in the pathway and its direct link to B cell survival through NF- $\kappa \mathrm{B}[7,8]$. In humans, Btk plays a critical role in the development of $B$ cells and subsequent antibody production, and mutation of the Btk gene results in X-linked agammaglobulinemia, which is characterized by low peripheral B cell numbers as well as low serum immunoglobulin titers [9]. Similarly, mutation or deletion of the Btk gene in mice leads to $\mathrm{X}$-linked immunodeficiency (xid), characterized by a significant decrease in B1 and B2 B cells as well as significantly decreased serum immunoglobulin levels [9]. Although Btk is expressed in other hematopoietic lineages (but not $\mathrm{T}$ cells), the clinical phenotype of these genetic conditions is dominated by B cell immunodeficiency. It has long been appreciated that Btk is necessary for the production of autoantibodies in multiple murine models of lupus [10-12], and more recently it has been shown that constitutive activation of Btk in B cells results in the accumulation of autoreactive plasma cells [13]. Cell type-specific overexpression of Btk in B cells has recently been shown to lead to spontaneous germinal center and plasma cell formation, followed by autoantibody production [14]. However, even partial restoration of Btk by a low dose transgene in lyn/btk-double deficient mice results in abrogation of anti-nuclear antibodies [15]. Given the connection between B cell over-activity and various disease states, Btk has been investigated as a pathogenic target in multiple disease models. To this end, xid mice have been reported to be resistant to collagen-induced arthritis [16], and inhibition of Btk has been shown to be effective in treating various cancers as well as autoimmune diseases [17-20].

The NZM2410 mouse strain develops spontaneous lupus nephritis that shares a number of characteristics with human SLE [21]. Linkage analysis has uncovered several chromosomal intervals responsible for conferring lupus susceptibility in this strain [22]. By introgressing these intervals onto the healthy lupus-resistant C57BL/6 (B6) mouse strain, researchers have been able to determine the role of each locus in disease development. The presence of the Sle1 locus on the B6 background has been shown to be responsible for breaching immune tolerance to nuclear antigens. These mice display increased autoantibodies specific for chromatin, autoreactive $\mathrm{T}$ cells responding to histone epitopes, and enhanced expression of activation markers on $\mathrm{T}$ and $\mathrm{B}$ cells leading to functional defects in both cell types [23,24]. Meanwhile, the Sle3 locus introgressed onto the B6 background demonstrates dysregulated $\mathrm{T}$ cells as evidenced by hyperactivity and skewed CD4:CD8 ratios as a result of hyper-stimulatory antigen presenting cells (APCs) $[25,26]$. The Sle 3 locus also confers some resistance to bacterial infections, further suggesting a role for this locus in the proper functioning of APCs [27]. Taken together, these data suggest a predominantly B cell-mediated role for the Sle1 locus and a predominantly innate immunity-targeted role for the Sle3 locus in lupus development. While the introduction of any single NZM2410-derived locus has not been shown to recapitulate complete disease, the presence of both the Sle 1 locus and the Sle3 locus on the B6 background results in severe glomerulonephritis, reinforcing the notion that multiple genetic alterations in several cell types may be necessary to drive lupus pathogenesis [28].

Here, we have utilized mouse models bearing these lupus susceptibility loci to investigate the therapeutic potential of Btk in a spontaneous murine model of lupus nephritis by treating the mice with a small molecule Btkinhibitor, PCI-32765; this is an irreversible inhibitor that binds covalently to Cys- 481 of Btk with an IC50 of about $0.5 \mathrm{nM}$ in biochemical assays. PCI-32765 is currently in phase II trials for treatment of B cell malignancies, and preliminary results demonstrate that approximately 60 to $70 \%$ of patients with relapsed and refractory chronic lymphocytic leukemia (CLL) or mantle cell lymphoma (MCL) respond to the drug $[29,30]$.

\section{Materials and methods}

Mice

For these studies all mice were bred and housed at the University of Texas Southwestern Medical Center in Dallas, TX, USA. The studies were designed in conjunction with Pharmacylics, Inc. (Sunnyvale, CA, USA), and were conducted with the prior approval of the University of Texas Southwestern Medical Center Institutional Animal Care and Use Committee. Based on the typical age of phenotype development in these models 8-month-old male and female B6.Sle1 and pre-disease 4-month-old female B6.Sle1.Sle3 mice were used for the experiments. Autoantibody levels were examined prior to the start of treatment to ensure the mice were at similar stages of disease. Both sets of mice were treated for two months and then sacrificed to ensure that mice did not succumb to disease before the data could be collected.

\section{Drug formulation}

PCI-32765 (Pharmacyclics Inc.) was formulated in sterilefiltered 1\% HP-beta-cyclodextrin in distilled water. The drug was provided in drinking water at $0.16 \mathrm{mg} / \mathrm{mL}$, which is an estimated dose of $30 \mathrm{mg} / \mathrm{kg}$ calculated based on average water consumption. The vehicle was sterilefiltered 1\% HP-beta-cyclodextrin in distilled water. The amount of drug- or vehicle-containing water consumed was approximately 3.5 to $4.0 \mathrm{~mL}$ per mouse per day and 
was similar between groups and cages (data not shown). Splenocytes were isolated from B6.Sle1.Sle3 mice treated with PCI-32765 after sacrifice on day 56 and the pharmaco-dynamic probe assay for Btk was performed as previously described [17].

\section{Histopathology}

Kidneys isolated from 6-month-old B6.Sle1.Sle3 mice were cut laterally and fixed in phosphate-buffered $10 \%$ formalin, processed in paraffin blocks and cut into $5-\mu \mathrm{m}$ sections. Sections were stained with periodic-acid Schiff (PAS) or $H \& E$ and examined by light microscopy for evidence of inflammation or tissue damage. At least 100 glomeruli per section were examined and scoring ( 0 to 4 ) of renal damage was done by a pathologist blinded to the study, as detailed previously [31].

\section{Autoantibody ELISA}

Ninety-six-well plates were pre-coated with methylated BSA before the addition of double stranded DNA, single stranded DNA, histones, or double stranded DNA and then histones (nucleosomes) as detailed previously [31]. After incubation, the plates were washed, sera from the study mice were added to the wells, and the plates were again incubated. After washing off the unbound sera, alkaline phosphatase-conjugated goat anti-mouse IgG or IgM antibodies were added. Autoantibody titers were determined by the absorbance read at $405 \mathrm{~nm}$ on an ELx808 plate reader (BioTek, Winooski, VT, USA).

\section{Flow cytometry}

Spleens and kidneys were isolated from mice following sacrifice and perfusion. For the spleens, a single cell suspension was obtained by crushing the spleen through a 100micron mesh filter and washing the cells. Red blood cells were lysed using PharmLyse (BD Biosciences, San Diego, CA, USA). Kidneys were minced with a razor blade and treated with collagenase for 30 minutes at $37^{\circ} \mathrm{C}$ with shaking. Following collagenase treatment, cells were immediately placed on ice and the collagenase activity was stopped by dilution with media containing fetal bovine serum. Red blood cells were lysed in a similar manner to splenocytes and cell clumps were disrupted by syringe and then forced through a 100-micron filter. Cells were stained with antibodies against AA4.1, B220, CD4, CD5, CD8, CD11b, CD11c, CD21/35, CD23, CD34, CD45, CD62L, CD69, CD138, cKit, GL-7, Ly6C, Ly6G (BD Biosciences) and F4/80 (Invitrogen, San Diego, CA). All samples were run on an LSRII flow cytometer (BD Biosciences) in the University of Texas Southwestern Medical Center Flow Cytometry Core.

\section{Statistics}

All statistical analyses were done by two-tailed Student's t-test with Welch's correction.

\section{Results}

$\mathrm{PCl}-32765$ checks the increase in autoantibodies inherent to the Sle1 locus

While C57BL/6 mice do not spontaneously develop lupus, the presence of the Sle1 locus from the NZM2410 lupus-prone strain results in the development of autoantibodies, especially anti-histone and anti-nucleosome antibodies, as well as hyperactivated $\mathrm{T}$ and $\mathrm{B}$ cells $[23,24]$. Given that the Sle1 locus has previously been shown to be related to a defect in B cell tolerance, we targeted the proximal BCR-mediated signaling molecule Btk by treating B6.Sle1 mice with PCI-32765, to examine the impact of disrupting BCR-signaling on autoantibody development. Although IgM isotype anti-ssDNA, antinucleosome, and anti-histone antibodies did not show significant differences following treatment, PCI-32765treated mice demonstrated reduced levels of IgG isotype anti-histone, anti-nucleosome and anti-dsDNA levels, with the latter attaining statistical significance $(69 \%$ reduction, $P<0.05$ ), compared to day 0 levels in the same mice (Figure 1). In contrast, circulating levels of all measured autoantibodies increased in vehicle-treated mice over the same time period (Figure 1). Taken together these data indicate that Btk plays an important role in both autoantibody production and isotype switching, with a more profound impact on class-switched IgG autoantibodies. These data are similar to previous genetic studies demonstrating that reduced Btk gene dosage preferentially affects IgG antibodies in 56R anti-DNA transgenic mice but both IgM and IgG antibodies in lyn-/- mice $[15,32]$. Interestingly, the anti-histone and anti-nucleosome titers that are most affected by PCI-32765 treatment resemble the anti-nucleosome seroprofile previously attributed to Sle1 $[23,24]$.

\section{Inhibition of Btk results in a less severe Sle1 phenotype}

Although the Sle1-bearing mice do not develop full blown lupus-like disease, the Sle1 locus has been shown to elicit lymphocyte activation and splenomegaly [23]. B6.Sle1 mice treated with PCI-32765 have no significant change in total body weight compared to vehicle-treated mice (Figure 2A); however the PCI-32765-treated mice display a $43.3 \%$ decrease in spleen size and total splenocytes compared to the vehicle-treated mice $\left(4.90 \times 10^{7} \mathrm{vs}\right.$. $8.65 \times 10^{7}$ splenocytes, Figure $\left.2 \mathrm{~B}-\mathrm{C}\right)$. This reduction in cell number coincides with a decrease in activated CD4+ (28\%) and CD8+ (46\%) T-cells, activated B-cells (53\%), germinal center B-cells $(62 \%, P=0.05$, B220+GL7+), and plasmablasts (56\%) relative to the vehicle group (Figure 2D). However, the number of myeloid cells, including dendritic cells $(\mathrm{CD} 11 \mathrm{~b}+\mathrm{CD} 11 \mathrm{c}+)$, macrophages $(\mathrm{CD} 11 \mathrm{~b}+\mathrm{F} 4 / 80+)$, and neutrophils (CD11b+Ly6G+) is not significantly changed (data not shown). Taken together, these data suggest that Btk plays an important role in regulating immune cell 

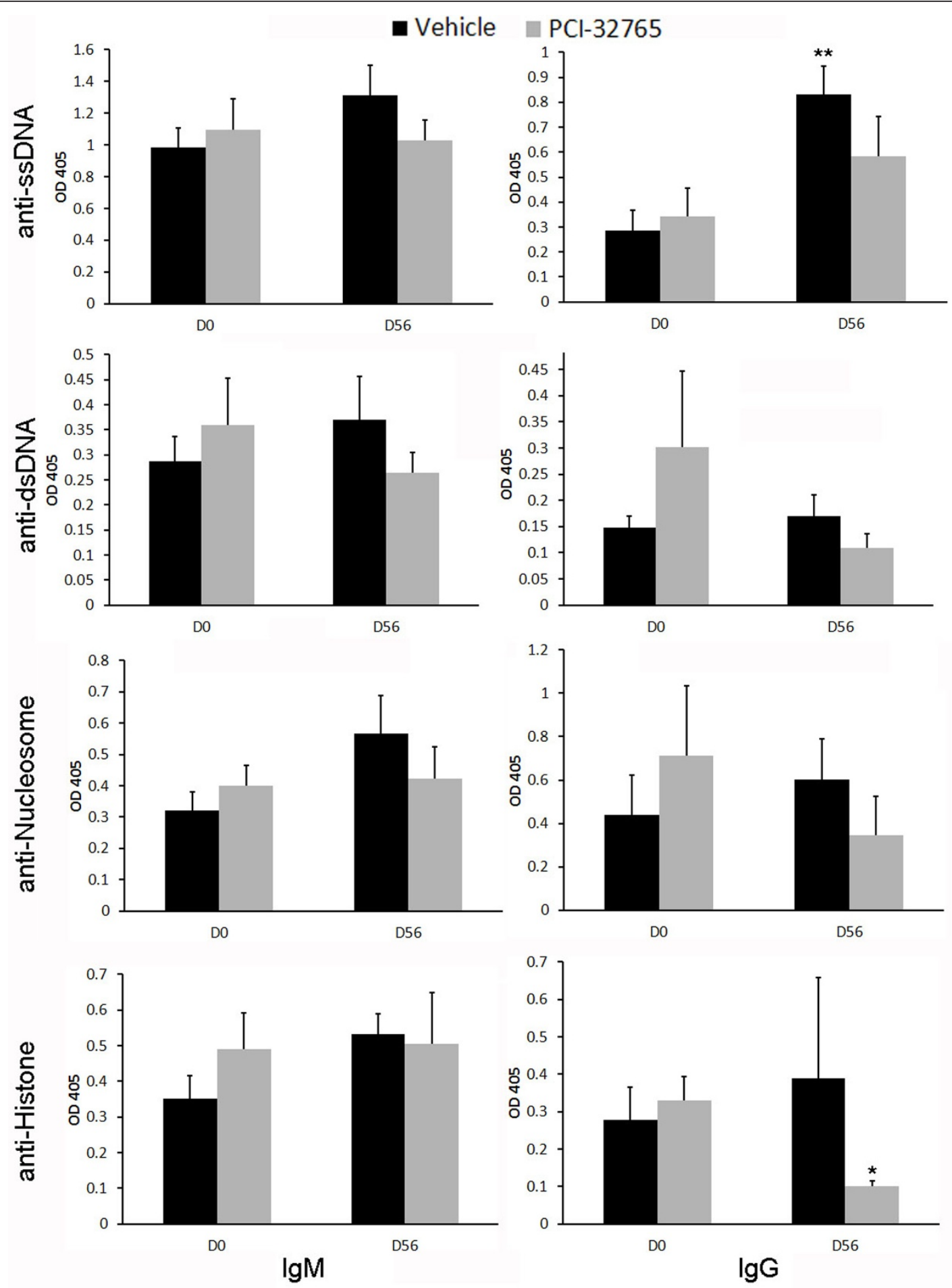

Figure 1 PCI-32765 dampens the production of anti-nuclear autoantibodies in B6.Sle1 mice. The indicated autoantibody ELISAs were performed on sera isolated at the indicated day of treatment from mice either treated with PCl-32765 (black bars, $n=5$ ) or a vehicle (grey bars, $n=4)$. All values are the optical density $(\mathrm{OD})$ readings at $405 \mathrm{~nm}$ wavelength. ${ }^{*} P<0.05$, ${ }^{* *} P<0.01$ compared to day- 0 values measured in the same mice. D0, day zero; D56, day 56. 


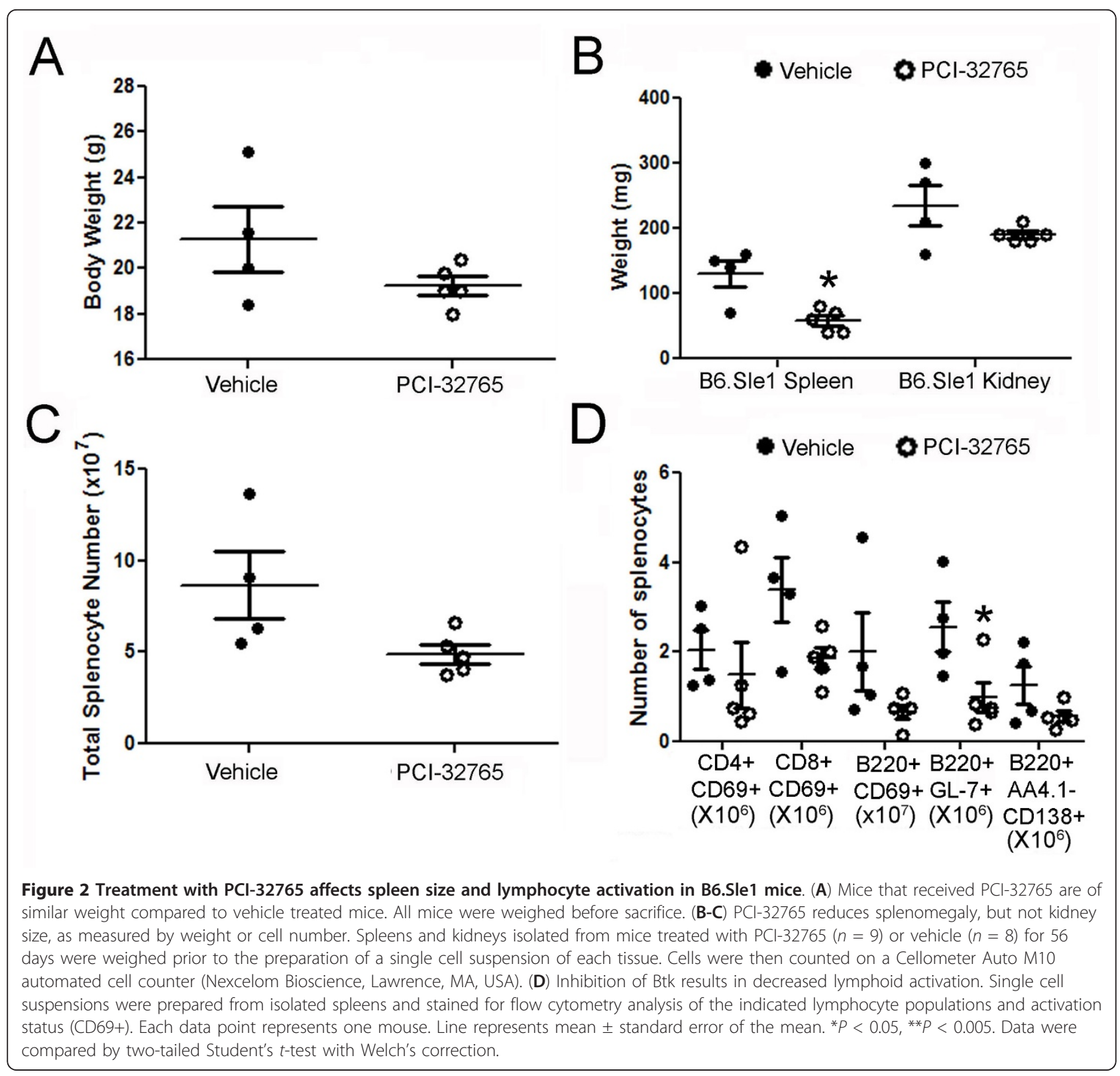

activation in the context of lupus, affecting multiple cell lineages.

\section{PCl-32765 delays production of circulating autoantibodies in Sle1.Sle3 bicongenic mice}

Though Sle1 by itself is not sufficient for full-blown lupus to ensue, bicongenics bearing both Sle1 and Sle3 develop lupus nephritis, likely as a result of a cumulative impact on multiple cell types including both B cells and APCs [33]. Given that the B6.Sle1.Sle3 mouse strain develops more severe disease with spontaneous glomerulonephritis around 6 months of age, we next treated 4month-old (pre-disease) B6.Sle1.Sle3 mice for 2 months with either PCI-32765 $(n=9)$ or a vehicle $(n=8)$ to determine if disease progression could be delayed or halted. Following treatment, splenocytes from the mice were isolated and assayed to ensure that PCI-32765 was binding Btk as previously reported (Figure 3A) [17]. Mice that had been treated with the vehicle displayed a thick band representative of unbound Btk. However, B6. Sle1.Sle3 mice that received drinking water containing PCI-32765 had significantly lighter bands, suggesting that Btk had been bound by PCI-32765 in these mice. We determined by densitometry that an average of $78.4 \%$ of the Btk was bound by PCI-32765 in the treatment group compared to the vehicle-treated mice (Figure 3A). The total expression of Btk was not affected in the PCI32765-treated mice (Figure 3B). 


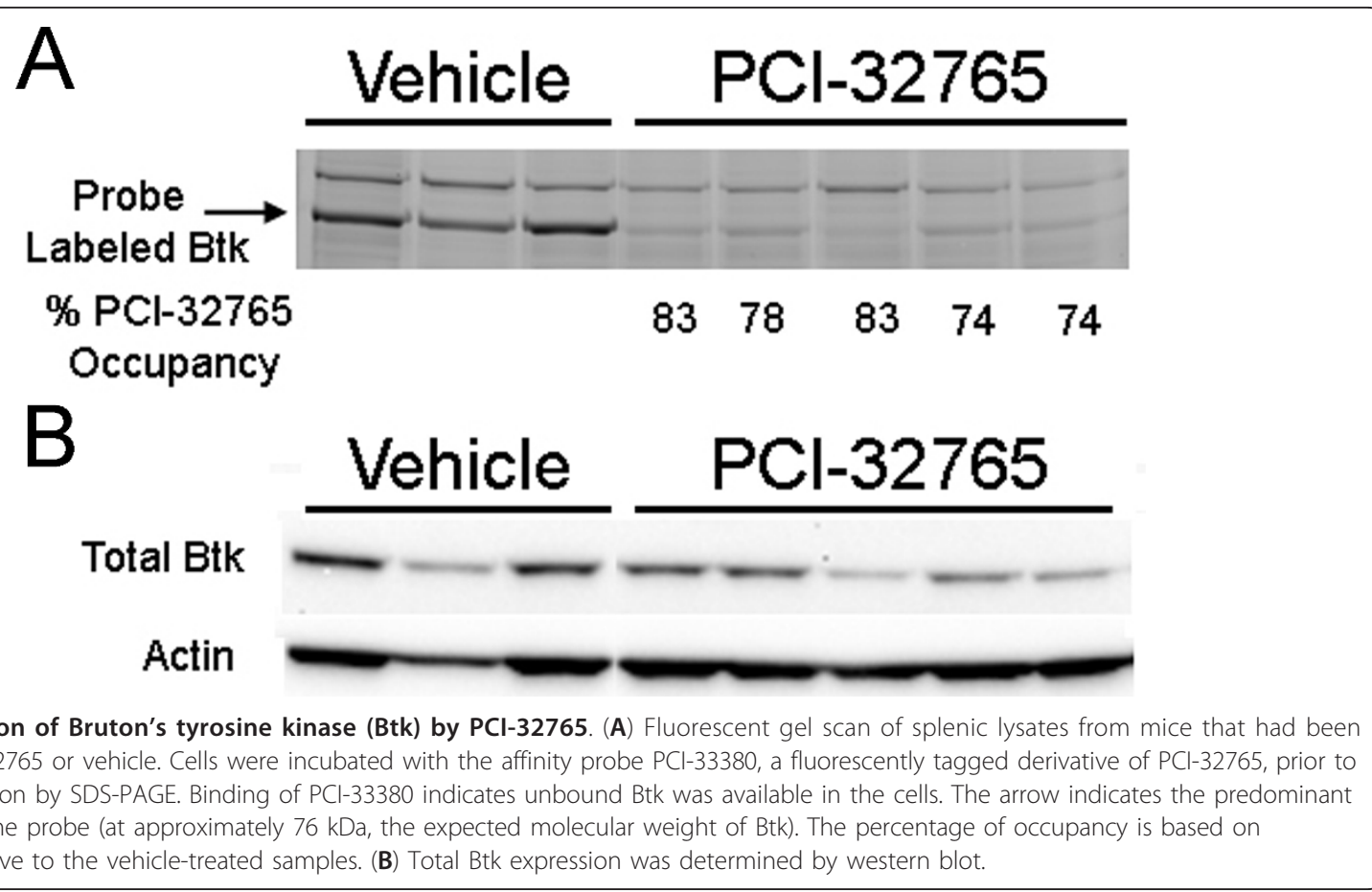

As noted in the B6.Sle1 treatment studies, Btk blockade also dampened autoantibody production in the bicongenic lupus strain. By day 28, the mice receiving the Btk-inhibitor displayed significantly reduced levels of both IgM and IgG anti-nucleosome and anti-histone antibodies (Figure 4). This reduction of circulating anti-nucleosome and anti-histone antibodies was sustained through day 56 , by which time point anti-ssDNA (but not anti-dsDNA) antibodies were also reduced (Figure 4).

PCl-32765 reduces splenomegaly and leukocyte activation in lupus-prone Sle1.Sle3 mice

After two months of treatment, spleen weights of the sacrificed animals were reduced by $58 \%$ in the treated mice (84.4 mg vs. $199 \mathrm{mg}, P=0.005$, Figure 5B). Splenic cell count was reduced by $70 \%\left(1.94 \times 10^{8}\right.$ vs. $5.9 \times 10^{7}$, $P=0.008)$ in these mice compared to the vehicle-treated mice (Figure $5 \mathrm{C}$ ). In contrast, the size and cellularity of the kidneys were not significantly reduced by PCI-32765 treatment, nor was the overall body weight (Figure 5A-C).

Flow cytometric analysis revealed significant decreases in splenic populations of multiple cell types in mice treated with PCI-32765 (Table 1), including total splenic B cells (71.5\%, $P<0.05)$, activated B cells $(74.9 \%, P<0.01)$, and B cells from multiple stages of development including T1 (64\%, $P<0.05)$ and T2 transitional B cells $(78.6 \%, P<$ $0.01)$, mature marginal zone $(74.6 \%, P<0.05)$ and follicular B cells $(63.2 \%, P<0.05)$, and plasmablasts $(74.5 \%, P<$ $0.01)$. Given that Btk has also been described in multiple myeloid cell types, these cell populations were also examined in mice treated with PCI-32765 $(n=9)$ compared to vehicle-treated mice $(n=8)$. Significant decreases were observed in myeloid dendritic cells $(79.2 \%, P<$ $0.005)$, macrophages $(76.4 \%, P<0.01)$, neutrophils $(68.1 \%$, $P<0.01)$, mast cells $(80.3 \%, P<0.02)$, and CD11b+Ly6C + CD62L- (73.6\%, $P<0.05)$ cells, which may represent newly infiltrating inflammatory monocytes, as summarized in Table 1. Interestingly, despite the lack of a T cell specific role for Btk, multiple splenic $\mathrm{T}$ cell populations from both $\mathrm{T}$ helper and cytotoxic $\mathrm{T}$ cell lineages were also impacted by treatment with PCI-32765. These significantly reduced $\mathrm{T}$ cell populations included total $\mathrm{T}$ helper cells (82.7\%, $P<0.01)$, activated T helpers $(83.6 \%, P<0.005)$, and both central $(84.6 \%, P<0.05)$ and effector $(80.5 \%, P<$ $0.01)$ memory $\mathrm{T}$ helper cells as well as total $(80.8 \%, P<$ $0.01)$, central memory $(75.5, P<0.01)$ and effector memory $(80.1 \%, P<0.01)$ cytotoxic T cells (Table 1$)$. Strikingly, despite the significant decrease in splenic size following PCI-32765 treatment, there was no difference in the number of naïve CD4+ T helper or naïve CD8+ cytotoxic $\mathrm{T}$ cell populations. Taken together, these data suggest that treatment with PCI-32765 skews T cells towards a less activated phenotype, likely as a result of decreased B cell and APC activation.

\section{Reduced renal damage and lymphocyte infiltration in PCl-32765-treated mice}

To determine if treatment with PCI-32765 was able to limit renal damage, paraffin-embedded kidneys from B6. Sle1.Sle3 mice treated with either PCI-32765 $(n=9)$ or 

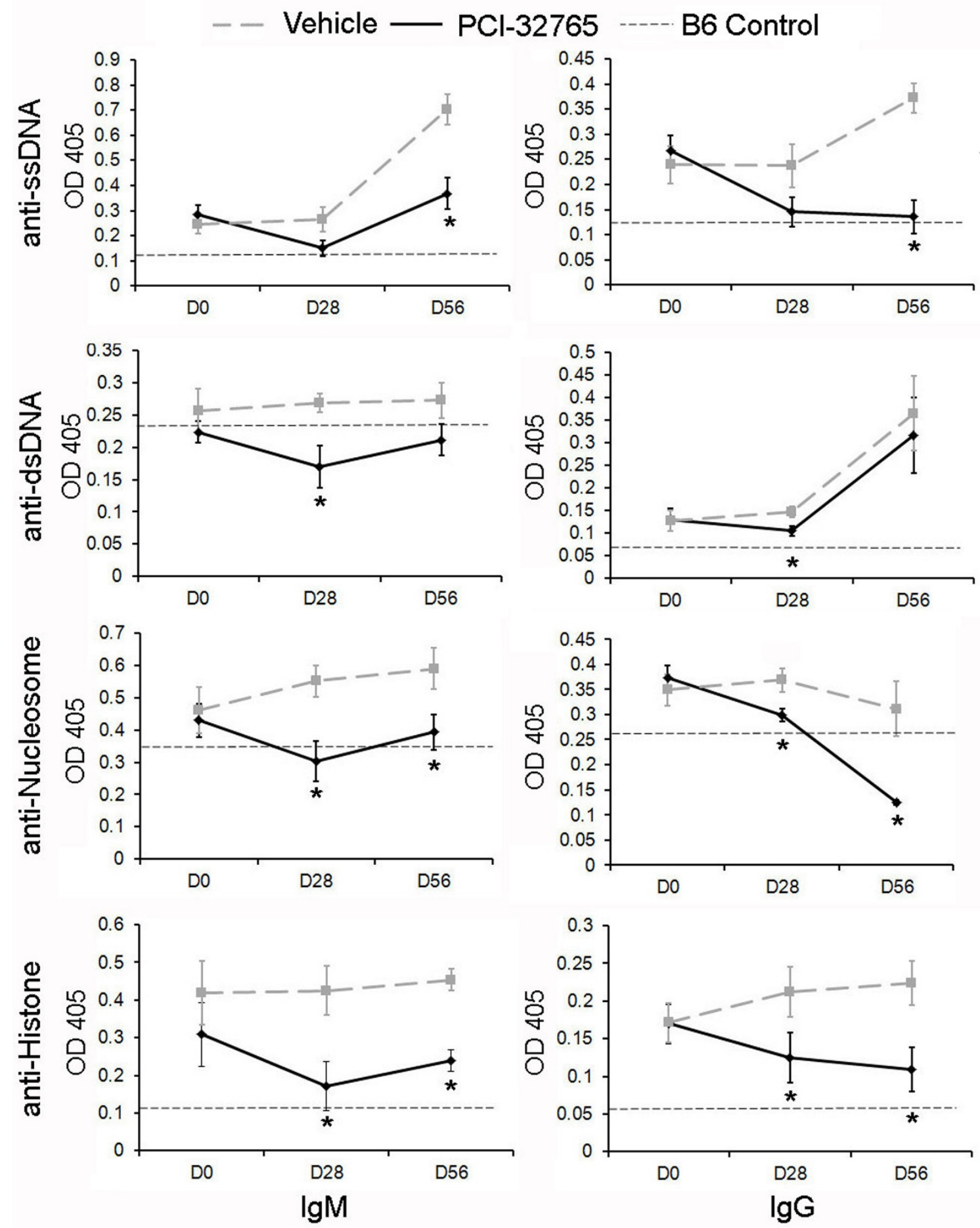

Figure 4 Inhibition of Btk limits increase of IgM isotype autoantibodies and results in decrease of IgG isotype autoantibodies in B6. Sle1.Sle3 mice. The indicated autoantibody ELISAs were performed on sera routinely isolated from mice either treated with PCl-32765 or vehicle. All values are the optical density (OD) readings at $405 \mathrm{~nm}$ wavelength. Thick grey dashed line indicates vehicle, black line indicates $\mathrm{PCl}$-32765. Thin dashed line indicates serum antibodies in 2-month-old lupus-resistant B6 sample indicative of negative control. All data points represent the mean \pm standard error of the mean. ${ }^{*} P<0.05$. Samples were compared by two-tailed Student's $t$-test with Welch's correction. D0, day zero, D28, day 28; D56, day 56. 

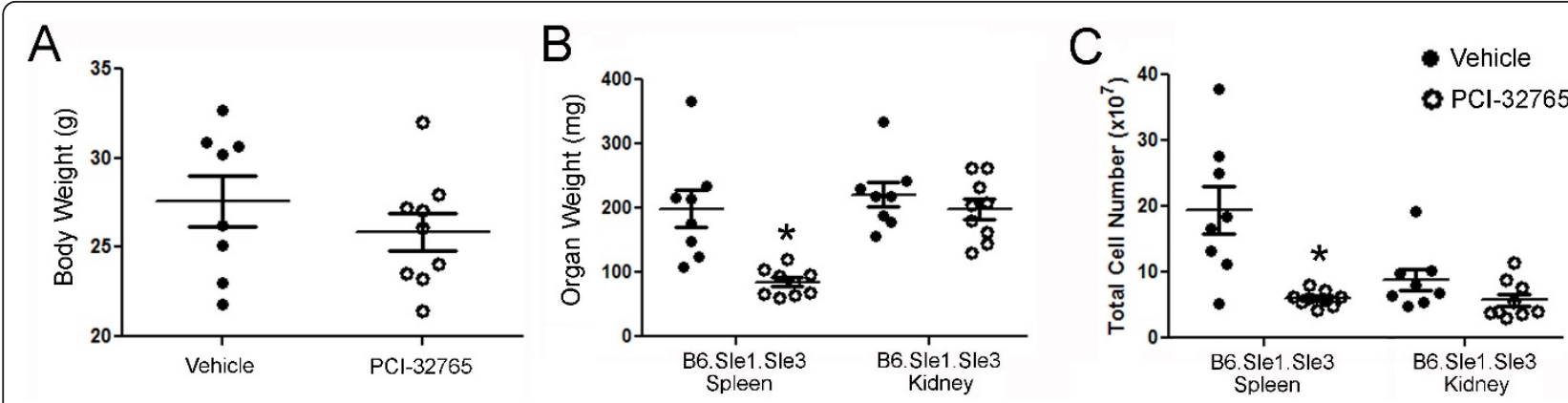

Figure 5 Treatment of B6.Sle1.Sle3 mice with PCl-32765 results in reduction of splenomegaly. (A) PCl-32765 has no effect on mouse weight. All mice were weighed before sacrifice. (B-C) PCl-32765 reduces splenomegaly, but not kidney size, as measured by weight or cell number. Spleens and kidneys isolated from mice treated with PCl-32765 $(n=9)$ or vehicle $(n=8)$ were weighed prior to the creation of a single cell suspension of each tissue. Cells were then counted on a Cellometer Auto M10 automated cell counter (Nexcelom Bioscience). Each data point represents one mouse. Line represents mean \pm standard error of the mean. ${ }^{*} P<0.05,{ }^{* *} P<0.005$. Data were compared by two-tailed Student's t-test with Welch's correction.

vehicle $(n=6)$ were sectioned, stained and scored by a pathologist who remained blind to sample identities. While the kidneys from the vehicle-treated mice had moderate damage (glomerular nephritis (GN) score $2.67 \pm 0.25, n=6)$, the PCI-32765-treated mice displayed significantly less renal damage (GN score $1.39 \pm$ 0.16, $n=9, P<0.02$, Figure $5 \mathrm{~A}, \mathrm{C})$. There was also a corresponding decrease in the number of infiltrating lymphocytes in the kidneys. Despite similar numbers of total intra-renal cells in both groups (Figure 6A), there were significantly fewer B220+ B-cells (59\% decrease, $P<0.01)$ in the kidneys of B6.Sle1.Sle3 mice that received PCI-32765 compared to mice that received the vehicle (Figure 6B).

\section{Discussion}

When cells are initially confronted with antigens, each cell is at a crossroads from which the cell can either become activated and begin an immune response, or be eliminated through anergy induction or apoptosis. Autoimmunity at its most basic level, is characterized by the improper response to self-antigens leading to activation of an immune response. Historically, treatment for SLE has been limited to general immune suppressive drugs, including corticosteroids, anti-malarial drugs, and cyclophosphamide, all of which are limited in their efficacy and are associated with deleterious side effects [34]. The recent US Food and Drug Administration (FDA) approval of belimumab, an inhibitor of B lymphocyte stimulator (BLyS), for the treatment of SLE patients has highlighted a new wave of signaling targets that are being therapeutically exploited with some encouraging results in lupus. These novel candidates include a variety of intracellular proteins such as calmodulin kinase, calcineurin, heat shock protein 90 and Rho, as reviewed [34,35]. In B cells, one potential mechanism for accomplishing this is to disrupt BCR signaling, as the $\mathrm{BCR}$ is responsible for delivering maturation signals to immature and mature B cells. Inhibition of the BCR-component, spleen tyrosine kinase (Syk), has shown promise in attenuating skin and renal manifestations of lupus in certain mouse models [36], although translation to human trials may be complicated by the expression of Syk on a number of cell types. Another such target within the BCRsignaling cascade is Btk.

Btk is a particularly attractive target in this signaling cascade because it has a specific role in B cell activation and survival. While xid- and Btk-deficient mice display a marked reduction in mature $B$ cells in the periphery, these mice have normal numbers of pre-B and immature B cells $[37,38]$. Furthermore, the loss of Btk function dampens the ability of B cells to respond to signals from cell surface receptors including the $\mathrm{BCR}, \mathrm{IL}-10 \mathrm{R}, \mathrm{RP} 105, \mathrm{CD} 38$, and toll-like receptors (TLRs), amongst others [39-43]. Thus, the addition of a Btk transgene to Btk-deficient mice restores the mature $B$ cell population but still does not restore full response to BCR signals [44]. B cell response to $\mathrm{T}$-independent antigens are also reliant on Btk in a dose-dependent fashion, as partial restoration of Btk restores normal $\mathrm{B}$ cell response to type-II viral antigens but not 2,4,6-trinitrophenol (TNP)-Ficoll. Taken together, these data suggest that modulation of Btk levels can differentially affect B-cell differentiation, survival, and function without eliminating the majority of mature B-cells. Therefore, our goal was to modulate, rather than completely block, BCR signaling. Such inhibition of BTK with PCI32765 has recently been shown to be efficacious in patients with B cell malignancies $[19,45]$ as well as in mice with autoimmune diseases $[17,20]$.

Previously the Sle1 locus has been identified as being crucial in breaking peripheral B cell tolerance [46]. Thus, the B6.Sle1 mouse is a particularly attractive model for testing the ability of Btk inhibition to modulate the 
Table 1 Analysis of surface phenotype of splenocytes

\begin{tabular}{|c|c|c|c|c|c|}
\hline \multirow[b]{2}{*}{ B cells } & \multicolumn{4}{|c|}{ Cell Number/Spleen } & \multirow[b]{2}{*}{$P$-value } \\
\hline & $\begin{array}{c}\text { Average } \\
\text { Vehicle }\end{array}$ & SEM Vehicle & Average $\mathrm{PCl}-32765$ & SEM PCI-32765 & \\
\hline $\bar{B} 220+$ & $3.97 \mathrm{E}+07$ & $1.13 \mathrm{E}+07$ & $9.06 \mathrm{E}+06$ & $2.76 \mathrm{E}+06$ & * \\
\hline Activated, B220+CD69+ & $3.71 \mathrm{E}+06$ & $9.33 \mathrm{E}+05$ & $5.29 \mathrm{E}+05$ & $9.19 E+04$ & $* *$ \\
\hline T1, B220+AA4.1+CD23- & $1.64 \mathrm{E}+07$ & $5.90 \mathrm{E}+06$ & $2.95 \mathrm{E}+06$ & $8.72 \mathrm{E}+05$ & * \\
\hline T2, B220+AA4.1+CD23+ & $1.60 \mathrm{E}+07$ & $3.42 \mathrm{E}+06$ & 4.02E+06 & $1.79 \mathrm{E}+06$ & $* *$ \\
\hline Marginal zone, B220+AA4.1-CD23- & $1.99 \mathrm{E}+06$ & $5.05 E+05$ & $5.25 E+05$ & $1.92 \mathrm{E}+05$ & * \\
\hline Follicular, B220+AA4.1-CD23+ & $5.13 \mathrm{E}+06$ & $1.89 \mathrm{E}+06$ & $8.82 E+05$ & $2.18 \mathrm{E}+05$ & * \\
\hline Plasmablast, B220+AA4.1-CD138+ & $3.62 E+06$ & $9.24 \mathrm{E}+05$ & 4.36E+05 & 7.13E+04 & $* *$ \\
\hline Germinal center, B220+GL7+ & $8.61 \mathrm{E}+06$ & 4.52E+06 & $8.72 \mathrm{E}+05$ & $3.38 \mathrm{E}+05$ & NS \\
\hline B1-like, B220+CD5+ & $1.01 \mathrm{E}+06$ & $2.62 \mathrm{E}+05$ & $2.60 \mathrm{E}+05$ & $3.93 \mathrm{E}+04$ & * \\
\hline \multicolumn{6}{|l|}{ Myeloid } \\
\hline Myeloid DC, CD11b+CD11c+ & $1.33 \mathrm{E}+07$ & $2.76 \mathrm{E}+06$ & $2.19 \mathrm{E}+06$ & 4.28E+05 & $* * *$ \\
\hline Macrophage, CD11b+F4/80+ & $1.32 \mathrm{E}+07$ & $3.11 \mathrm{E}+06$ & $2.15 \mathrm{E}+06$ & $3.88 \mathrm{E}+05$ & ** \\
\hline CD11b+Ly6C+ & $1.74 \mathrm{E}+06$ & $5.54 \mathrm{E}+05$ & $3.40 \mathrm{E}+05$ & $6.72 \mathrm{E}+04$ & * \\
\hline Neutrophils, CD11b+Ly6G+ & $1.50 \mathrm{E}+07$ & $3.51 \mathrm{E}+06$ & $2.41 \mathrm{E}+06$ & 4.16E+05 & ** \\
\hline Mast cell, CD34+c-Kit+ & $3.74 \mathrm{E}+06$ & $9.87 E+05$ & $7.36 \mathrm{E}+05$ & $2.54 \mathrm{E}+05$ & * \\
\hline \multicolumn{6}{|l|}{$\mathrm{T}$ cells } \\
\hline CD4+ & $2.31 \mathrm{E}+07$ & 4.00E+06 & $9.83 \mathrm{E}+06$ & $9.76 \mathrm{E}+05$ & $* *$ \\
\hline Activated, CD4+CD69+ & $8.29 \mathrm{E}+06$ & $1.36 \mathrm{E}+06$ & $2.64 \mathrm{E}+06$ & $1.01 E+06$ & $* * *$ \\
\hline Naïve, CD4+CD44-CD62L+ & $9.73 E+05$ & 2.34E+05 & $5.68 \mathrm{E}+05$ & $9.45 \mathrm{E}+04$ & NS \\
\hline Central memory, CD4+CD44+CD62L+ & $5.11 \mathrm{E}+06$ & 7.89E+05 & $2.84 \mathrm{E}+06$ & $3.49 \mathrm{E}+05$ & * \\
\hline Effector memory, CD4+CD44+CD62L- & $1.56 \mathrm{E}+07$ & $3.04 \mathrm{E}+06$ & $6.00 \mathrm{E}+06$ & $7.58 \mathrm{E}+05$ & $* *$ \\
\hline CD8+ & $2.01 \mathrm{E}+07$ & $3.86 \mathrm{E}+06$ & $5.29 \mathrm{E}+06$ & $8.23 E+05$ & ** \\
\hline Activated, CD8+CD69+ & $8.57 E+06$ & $1.60 \mathrm{E}+06$ & $2.54 \mathrm{E}+06$ & 1.17E+06 & $* *$ \\
\hline Naïve, CD8+CD44-CD62L+ & $6.18 \mathrm{E}+03$ & $3.33 \mathrm{E}+03$ & $3.34 \mathrm{E}+03$ & $2.65 \mathrm{E}+03$ & NS \\
\hline Central memory, CD8+CD44+CD62L+ & $5.64 \mathrm{E}+06$ & $1.38 \mathrm{E}+06$ & $9.08 \mathrm{E}+05$ & $1.65 \mathrm{E}+05$ & $* *$ \\
\hline Effector memory, CD8+CD44+CD62L- & $1.45 \mathrm{E}+07$ & $2.87 \mathrm{E}+06$ & $4.38 \mathrm{E}+06$ & $8.23 E+05$ & $* *$ \\
\hline
\end{tabular}

Quantitative analysis of B6.Sle1.Sle3 splenic cell populations as determined by flow cytometry. All data are expressed as the mean (Average) and standard error of the mean (SEM) of the data for the PCI-32765-treated $(n=9)$ or vehicle-treated $(n=8)$ splenocytes, which were compared by two-tailed Student's $t$-test. ${ }^{*} P \leq$ $0.05,{ }^{* *} P \leq 0.01,{ }^{* * *} P \leq 0.005$, compared to vehicle; NS, not significant.

humoral autoimmunity associated with lupus. Upon treatment with PCI-32765, inhibition of Btk resulted in a dampening of the Sle1-associated phenotype at both the cellular and serological levels. It is clear from these studies in B6.Sle1 mice that Btk in B-cells is a critical B-cell activation node in lupus development. While B6.Sle1 mice provide a model to investigate the role of humoral immunity in SLE, single congenic Sle1 mice do not fully develop lupus nephritis. Hence, the B6.Sle1.Sle3 bicongenic mouse model, which develops a more robust lupus-like phenotype was next utilized. This model was well suited to this study given the previously reported roles of Btk in myeloid cell activation, and established myeloid cell population defects attributed to the Sle3 locus. Importantly, PCI-32765 treatment markedly reduces spleen size and renal infiltration of leukocytes as well as renal damage in B6.Sle1.Sle3 mice. In these studies, we have observed a decrease in all peripheral B cell populations in the $\mathrm{PCI}-32765$ treated mice compared to the vehicle, although B-cell development appears to be relatively normal. Consistent with genetic data from Btk ${ }^{\text {low }}$ mice, these data suggest that a partial Btk signal is enough to permit B-cell development while still managing to regulate the overall number of mature and activated $B$ cells [15]. Btk inhibition led to significantly reduced numbers of splenic plasmablasts (Table 1), consistent with previous findings that Btk is necessary for antibody production in a gene dosage-dependent manner $[13-15,32,47]$.

Contrary to a previous report, which suggested that Btk repressed dendritic cell maturation and increased $\mathrm{T}$ helper cell activation by dendritic cells [48], we found that PCI32765 treatment decreases splenic myeloid dendritic cells as well as $\mathrm{T}$ cell activation (Table 1); these data may suggest a dose-sensitive context for Btk in dendritic cells, similar to previous experiments with Btk ${ }^{\text {low }}$ mice in B cells $[12,15,44]$. We have also demonstrated that treatment with PCI-32765 significantly decreases the number of splenic mast cells, corresponding with previous data that demonstrate a role for Btk in mast cell activation [49]. 


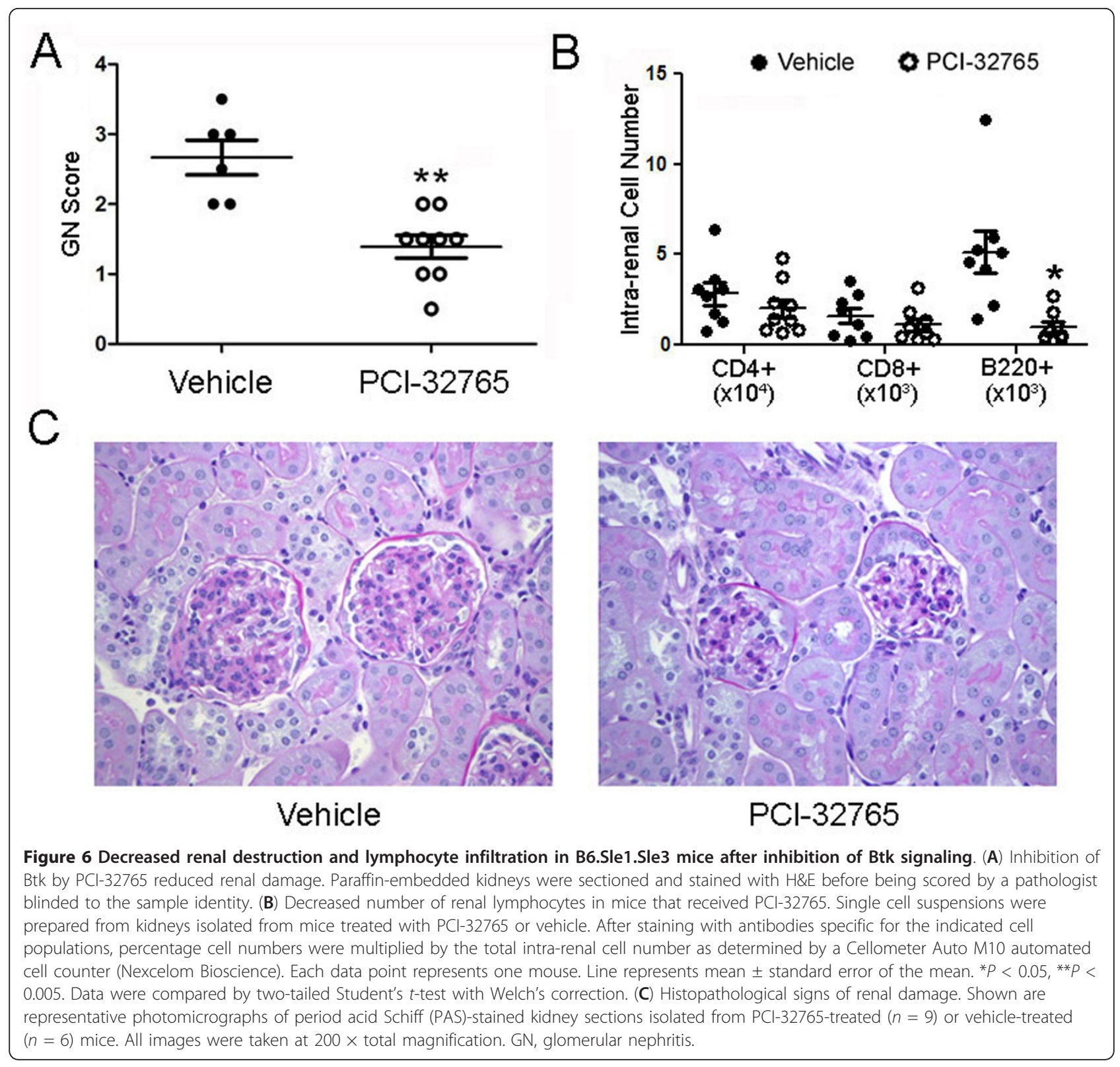

Taken together, these decreases in multiple immunocompetent cell populations, as well as the dampening of lymphocyte activation, underscore the ability of PCI-32765 to curtail the aberrant cellular activation that drives lupus pathogenesis.

Of note, inhibition of Btk also results in a decrease in Bcell infiltration into the kidney. It has previously been reported that intra-renal B-cells contribute to kidney damage and interstitial inflammation [50-52]. Likewise, renal damage was reduced in B6.Sle1.Sle 3 mice that received PCI-32765 compared to the vehicle, as evidenced by decreased $\mathrm{GN}$ score and decreased glomerular size (Figure 6A, C). However, given that splenic myeloid cell populations are also decreased (Table 1) it is possible that some of the beneficial effects of Btk inhibition may arise from its impact on the myeloid cell compartment, which also entails Btk signaling for optimal functioning. It has previously been shown that Btk is involved in various myeloid cell-mediated processes in mast cells [1], neutrophils $[2,3]$, and macrophages $[4,5]$, including bacterial clearance, production of reactive oxygen species (ROS), and TLR signaling. Moreover, PCI-32765 has previously been shown to exert effects on myeloid cells in the prevention of experimental arthritis [20].

In summary, we have shown that treatment of lupusprone mice with PCI-32765 results in greater than 75\% inhibition of Btk, which is sufficient to reduce autoantibody titers, similar to Btk ${ }^{\text {low }}$ mice, which express $25 \%$ of 
endogenous Btk levels [12,53]. This is accompanied by marked reduction in both the number and the activation status of $\mathrm{T}$ and $\mathrm{B}$ cells as well as the number of myeloid cells. Since T cells lack Btk expression, it seems likely that the decreased number and activation status of $\mathrm{T}$ cells is a result of decreased activation cues from B cells and APCs. Meanwhile, it seems plausible that the decrease in $B$ cell and APC numbers may be caused by either decreased expansion resulting from suboptimal activation, increased apoptosis, or both. Previous reports lend support to both mechanisms as Btk has been shown to be critically important in both myeloid [1-5] and B cell activation [13,14,50] as well as in the negative regulation of apoptotic processes. Relevant to our data, Btk is required for BCR-mediated NF- $\kappa \mathrm{B}$ pro-survival signaling $[7,8,54]$, and is an upstream regulator of the anti-apoptotic protein bcl-xL in B cells following IgM stimulation [55]. Btk is also necessary for the survival of macrophages following inflammatory stimulation [56], and is a regulator of the ROS response in both B cells [57] and neutrophils [58]. Furthermore, in vitro PCI32765 treatment of CD19+ cells isolated from patients with CLL resulted in increased apoptosis in a dose-dependent manner [19]. Thus, subdued proliferative expansion as well as enhanced apoptosis could both have contributed to the cellular changes observed following Btk inhibition in lupus, and this warrants further systematic evaluation.

Taken together these data suggest that Btk signaling, as a key mediator of B cell activation, antibody production, and myeloid cell activation, is vital to the pathogenesis of SLE. Modulating BCR-mediated and APC signaling and/or survival by Btk inhibition results in decreased lymphoid activation and expansion, without total depletion. Given that total B cell depletion may not be optimal in SLE [6], fine-tuning the responsiveness of these cells as opposed to eliminating them completely may be a more viable therapeutic strategy in SLE. Therapeutically reducing the number of B cells to blunt autoimmunity comes with the inherent risk of eliminating the natural ability to produce antibodies against invading pathogens. Given that B cell and plasmablast populations are decreased but not completely eliminated following PCI-32765 treatment, it is likely that some degree of humoral immunity is preserved in these animals; nevertheless, further investigation is necessary to determine the full impact of PCI-32765 treatment on both the primary and secondary immune responses.

\section{Conclusions}

PCI-32765 treatment significantly decreased the amount of free Btk, and this dampened the development and activation of multiple peripheral cell types in the immune system, and decreased lupus severity as indicated by reduced autoantibody levels, splenomegaly, and renal disease. Therefore, targeting Btk to decrease downstream signaling in multiple cell types may be an effective therapeutic approach in SLE.

\section{Abbreviations}

APC: antigen presenting cell; BCR: B cell receptor; BLys: B lymphocyte stimulator; BSA: bovine serum albumin; Btk: Bruton's tyrosine kinase; CLL: chronic lymphocytic leukemia; ELISA: enzyme-linked immunosorbent assay; GN: glomerular nephritis; H\&E: hematoxylin and eosin; IL: interleukin; MCL: mantle cell lymphoma; PAS: period acid Schiff; ROS: reactive oxygen species; SLE: systemic lupus erythematosus; Syk: spleen tyrosine kinase; TLR: toll-like receptor; TNP: 2,4,6-trinitrophenol; xid: x-linked immunodeficiency.

\section{Acknowledgements}

This work was supported in part by NIH RO1 AR055600 and by Pharmacyclics.

\section{Author details}

${ }^{1}$ University of Texas Southwestern Medical Center, Department of Internal Medicine, Division of Rheumatic Diseases, 5323 Harry Hines Blvd., Dallas, TX 75390-8884, USA. ²Pharmacyclics, Inc., 995 East Arques Avenue, Sunnyvale, California 94085, USA. ${ }^{3}$ University of Texas Southwestern Medical Center, Department of Pathology, 5323 Harry Hines Blvd., Dallas, TX 75390 8884, USA.

\section{Authors' contributions}

JH supervised collection of mouse samples, acquired flow cytometry data, analyzed flow cytometry and immunoassay data, and drafted the manuscript. KV assisted in collection of mouse samples and carried out the immunoassays. AB, SG, and DS monitored mouse health and compound supply and assisted in collection of mouse samples. BYC assisted in study design, data interpretation, and manuscript preparation. JJB and ABS helped with data interpretation and manuscript preparation. XJZ and YD acquired and analyzed histology data. CM participated in the conception of the study, supervised the study and drafted the manuscript. All authors have read and approved the manuscript for publication.

\section{Competing interests}

BYC and JJB are employed by Pharmacylics Inc. and hold stock and/or stock options related to Pharmacyclics Inc. This study was partially funded by Pharmacylics Inc., which holds patents and patent applications related to $\mathrm{PCl}-32765$. All other authors have no competing interests to disclose.

Received: 1 June 2012 Revised: 13 August 2012

Accepted: 9 October 2012 Published: 8 November 2012

\section{References}

1. Iwaki S, Tkaczyk C, Satterthwaite AB, Halcomb K, Beaven MA, Metcalfe DD, Gilfillan AM: Btk plays a crucial role in the amplification of Fc epsilonRImediated mast cell activation by kit. J Biol Chem 2005, 280:40261-40270.

2. Mueller H, Stadtmann A, Van Aken H, Hirsch E, Wang D, Ley K, Zarbock A: Tyrosine kinase Btk regulates E-selectin-mediated integrin activation and neutrophil recruitment by controlling phospholipase C (PLC) gamma2 and PI3Kgamma pathways. Blood 2010, 115:3118-3127.

3. Fiedler K, Sindrilaru A, Terszowski G, Kokai E, Feyerabend TB, Bullinger L, Rodewald HR, Brunner C: Neutrophil development and function critically depend on Bruton tyrosine kinase in a mouse model of X-linked agammaglobulinemia. Blood 2011, 117:1329-1339.

4. Melcher M, Unger B, Schmidt U, Rajantie IA, Alitalo K, Ellmeier W: Essential roles for the Tec family kinases Tec and Btk in M-CSF receptor signaling pathways that regulate macrophage survival. J Immunol 2008, 180:8048-8056.

5. Vijayan V, Baumgart-Vogt E, Naidu S, Qian G, Immenschuh S: Bruton's tyrosine kinase is required for TLR-dependent heme oxygenase-1 gene activation via Nrf2 in macrophages. J Immunol 2011, 187:817-827.

6. Merrill JT, Neuwelt CM, Wallace DJ, Shanahan JC, Latinis KM, Oates JC, Utset TO, Gordon C, Isenberg DA, Hsieh HJ, Zhang D, Brunetta PG: Efficacy and safety of rituximab in moderately-to-severely active systemic lupus erythematosus: the randomized, double-blind, phase II/III systemic lupus 
erythematosus evaluation of rituximab trial. Arthritis Rheum 2010, 62:222-233.

7. Petro JB, Rahman SM, Ballard DW, Khan WN: Bruton's tyrosine kinase is required for activation of IkappaB kinase and nuclear factor kappaB in response to B cell receptor engagement. J Exp Med 2000, 191:1745-1754

8. Bajpai UD, Zhang K, Teutsch M, Sen R, Wortis HH: Bruton's tyrosine kinase links the B cell receptor to nuclear factor kappaB activation. J Exp Med 2000, 191:1735-1744.

9. Mohamed AJ, Yu L, Backesjo CM, Vargas L, Faryal R, Aints A, Christensson B, Berglof A, Vihinen M, Nore BF, Smith Cl: Bruton's tyrosine kinase (Btk): function, regulation, and transformation with special emphasis on the $\mathrm{PH}$ domain. Immunol Rev 2009, 228:58-73.

10. Seldin MF, Reeves JP, Scribner CL, Roths JB, Davidson WF, Morse HC, Steinberg AD: Effect of xid on autoimmune $\mathrm{C} 3 \mathrm{H}-\mathrm{gld} / \mathrm{gld}$ mice. Cell Immunol 1987, 107:249-255.

11. Steinberg BJ, Smathers PA, Frederiksen K, Steinberg AD: Ability of the xid gene to prevent autoimmunity in $(\mathrm{NZB} \times \mathrm{NZW}) \mathrm{F} 1$ mice during the course of their natural history, after polyclonal stimulation, or following immunization with DNA. J Clin Invest 1982, 70:587-597.

12. Satterthwaite $A B$, Lowell CA, Khan WN, Sideras P, Alt FW, Witte ON: Independent and opposing roles for Btk and lyn in B and myeloid signaling pathways. J Exp Med 1998, 188:833-844.

13. Kersseboom R, Kil L, Flierman R, van der Zee M, Dingjan GM, Middendorp S, Maas A, Hendriks RW: Constitutive activation of Bruton's tyrosine kinase induces the formation of autoreactive IgM plasma cells. Eur J Immunol 2010, 40:2643-2654.

14. Kil LP, de Bruijn MJ, van Nimwegen M, Corneth OB, van Hamburg JP, Dingjan GM, Thaiss F, Rimmelzwaan GF, Elewaut D, Delsing D, van Loo PF, Hendriks RW: Btk levels set the threshold for $B$ cell activation and negative selection of autoreactive B cells in mice. Blood 2012, 119:3744-3756.

15. Whyburn LR, Halcomb KE, Contreras CM, Lowell CA, Witte ON, Satterthwaite AB: Reduced dosage of Bruton's tyrosine kinase uncouples $B$ cell hyperresponsiveness from autoimmunity in lyn-/- mice. J Immunol 2003, 171:1850-1858.

16. Jansson L, Holmdahl R: Genes on the $X$ chromosome affect development of collagen-induced arthritis in mice. Clin Exp Immunol 1993, 94:459-465.

17. Honigberg LA, Smith AM, Sirisawad M, Verner E, Loury D, Chang B, Li S, Pan Z, Thamm DH, Miller RA, Buggy JJ: The Bruton tyrosine kinase inhibitor PCl-32765 blocks B-cell activation and is efficacious in models of autoimmune disease and B-cell malignancy. Proc Natl Acad Sci USA 2010, 107:13075-13080.

18. Di Paolo JA, Huang T, Balazs M, Barbosa J, Barck KH, Bravo BJ, Carano RA, Darrow J, Davies DR, DeForge LE, Diehl L, Ferrando R, Gallion SL, Giannetti AM, Gribling P, Hurez V, Hymowitz SG, Jones R, Kropf JE, Lee WP, Maciejewski PM, Mitchell SA, Rong H, Staker BL, Whitney JA, Yeh S, Young WB, Yu C, Zhang J, Reif $K$, et al: Specific Btk inhibition suppresses B cell- and myeloid cell-mediated arthritis. Nat Chem Biol 7:41-50.

19. Herman SE, Gordon AL, Hertlein E, Ramanunni A, Zhang X, Jaglowski S, Flynn J, Jones J, Blum KA, Buggy J, Hamdy A, Johnson AJ, Byrd JC: Bruton tyrosine kinase represents a promising therapeutic target for treatment of chronic lymphocytic leukemia and is effectively targeted by $\mathrm{PCl}$ 32765. Blood 2011, 117:6287-6296.

20. Chang BY, Huang MM, Francesco M, Chen J, Sokolove J, Magadala P, Robinson WH, Buggy JJ: The Bruton tyrosine kinase inhibitor PCl-32765 ameliorates autoimmune arthritis by inhibition of multiple effector cells. Arthritis Res Ther 2011, 13:R115.

21. Rudofsky UH, Evans BD, Balaban SL, Mottironi VD, Gabrielsen AE: Differences in expression of lupus nephritis in New Zealand mixed $\mathrm{H}-2 \mathrm{z}$ homozygous inbred strains of mice derived from New Zealand black and New Zealand white mice. Origins and initial characterization. Lab Invest 1993, 68:419-426.

22. Morel L, Rudofsky UH, Longmate JA, Schiffenbauer J, Wakeland EK: Polygenic control of susceptibility to murine systemic lupus erythematosus. Immunity 1994, 1:219-229.

23. Mohan C, Alas E, Morel L, Yang P, Wakeland EK: Genetic dissection of SLE pathogenesis. Sle1 on murine chromosome 1 leads to a selective loss of tolerance to H2A/H2B/DNA subnucleosomes. J Clin Invest 1998, 101:1362-1372

24. Sobel ES, Satoh M, Chen Y, Wakeland EK, Morel L: The major murine systemic lupus erythematosus susceptibility locus Sle1 results in abnormal functions of both B and T cells. J Immunol 2002, 169:2694-2700.
25. Mohan C, Yu Y, Morel L, Yang P, Wakeland EK: Genetic dissection of Sle pathogenesis: Sle3 on murine chromosome 7 impacts T cell activation, differentiation, and cell death. J Immunol 1999, 162:6492-6502.

26. Zhu J, Liu X, Xie C, Yan M, Yu Y, Sobel ES, Wakeland EK, Mohan C: T cell hyperactivity in lupus as a consequence of hyperstimulatory antigenpresenting cells. J Clin Invest 2005, 115:1869-1878.

27. Mehrad B, Park SJ, Akangire G, Standiford TJ, Wu T, Zhu J, Mohan C: The lupus-susceptibility locus, Sle3, mediates enhanced resistance to bacterial infections. J Immunol 2006, 176:3233-3239.

28. Mohan C, Morel L, Yang P, Watanabe H, Croker B, Gilkeson G, Wakeland EK: Genetic dissection of lupus pathogenesis: a recipe for nephrophilic autoantibodies. J Clin Invest 1999, 103:1685-1695.

29. O'Brien S, Burger JA, Blum KA, Furman RR, Coutre SE, Sharman J, Flinn IW, Grant B, Heerema NA, Johnson AJ, Navarro T, Holmgren E, Hedrick E, Byrd JC: The Bruton's tyrosine kinase (BTK) inhibitor PCl-32765 induces durable responses in relapsed or refractory $(R / R)$ chronic lymphocytic leukemia/small lymphocytic lymphoma (CLL/SLL): Follow-up of a phase Ib/ll study. 53rd Annual Meeting of the American Society of Hematology: December 13, 2011 Blood (ASH Annual Meeting Abstracts); 2011.

30. Wang L, Martin P, Blum KA, Kahl BS, Maeda LS, Advani R, Williams ME, Rule S, Rodriguez S, Pang C-F, Hedrick E, Goy A: The Bruton's Tyrosine Kinase Inhibitor PCl-32765 Is Highly Active As Single-Agent Therapy in Previously-Treated Mantle Cell Lymphoma (MCL): Preliminary Results of a Phase II Trial [abstract]. 53rd Annual Meeting of the American Society of Hematology: 2011 Blood (ASH Annual Meeting Abstracts); 2011.

31. Wu T, Qin X, Kurepa Z, Kumar KR, Liu K, Kanta H, Zhou XJ, Satterthwaite AB, Davis LS, Mohan C: Shared signaling networks active in B cells isolated from genetically distinct mouse models of lupus. J Clin Invest 2007, 117:2186-2196.

32. Halcomb KE, Musuka S, Gutierrez T, Wright HL, Satterthwaite AB: Btk regulates localization, in vivo activation, and class switching of anti-DNA B cells. Mol Immunol 2008, 46:233-241.

33. Morel L, Croker BP, Blenman KR, Mohan C, Huang G, Gilkeson G, Wakeland EK: Genetic reconstitution of systemic lupus erythematosus immunopathology with polycongenic murine strains. Proc Natl Acad Sci USA 2000, 97:6670-6675.

34. Lo MS, Tsokos GC: Treatment of systemic lupus erythematosus: new advances in targeted therapy. Ann NY Acad Sci 2012, 1247:138-152.

35. Kyttaris VC, Tsokos GC: Targeting lymphocyte signaling pathways as a therapeutic approach to systemic lupus erythematosus. Curr Opin Rheumatol 2011, 23:449-453.

36. Deng GM, Liu L, Bahjat FR, Pine PR, Tsokos GC: Suppression of skin and kidney disease by inhibition of spleen tyrosine kinase in lupus-prone mice. Arthritis Rheum 2010, 62:2086-2092.

37. Hardy RR, Hayakawa K, Parks DR, Herzenberg LA: Demonstration of B-cell maturation in $\mathrm{X}$-linked immunodeficient mice by simultaneous threecolour immunofluorescence. Nature 1983, 306:270-272.

38. Kerner JD, Appleby MW, Mohr RN, Chien S, Rawlings DJ, Maliszewski CR, Witte ON, Perlmutter RM: Impaired expansion of mouse B cell progenitors lacking Btk. Immunity 1995, 3:301-312.

39. Sieckmann DG, Asofsky R, Mosier DE, Zitron IM, Paul WE: Activation of mouse lymphocytes by anti-immunoglobulin. I. Parameters of the proliferative response. J Exp Med 1978, 147:814-829.

40. Go NF, Castle BE, Barrett R, Kastelein R, Dang W, Mosmann TR, Moore KW, Howard M: Interleukin 10, a novel B cell stimulatory factor: unresponsiveness of $X$ chromosome-linked immunodeficiency B cells. J Exp Med 1990, 172:1625-1631.

41. Miyake K, Yamashita Y, Hitoshi Y, Takatsu K, Kimoto M: Murine B cell proliferation and protection from apoptosis with an antibody against a 105-kD molecule: unresponsiveness of X-linked immunodeficient B cells. J Exp Med 1994, 180:1217-1224.

42. Santos-Argumedo L, Lund FE, Heath AW, Solvason N, Wu WW, Grimaldi JC, Parkhouse RM, Howard M: CD38 unresponsiveness of xid B cells implicates Bruton's tyrosine kinase (btk) as a regular of CD38 induced signal transduction. Int Immunol 1995, 7:163-170.

43. Jefferies CA, Doyle S, Brunner C, Dunne A, Brint E, Wietek C, Walch E, Wirth T, O'Neill LA: Bruton's tyrosine kinase is a Toll/interleukin-1 receptor domain-binding protein that participates in nuclear factor kappaB activation by Toll-like receptor 4. J Biol Chem 2003, 278:26258-26264. 
44. Satterthwaite $A B$, Cheroutre $H$, Khan WN, Sideras $P$, Witte ON: Btk dosage determines sensitivity to $B$ cell antigen receptor cross-linking. Proc Natl Acad Sci USA 1997, 94:13152-13157.

45. Advani RH, Sharman JP, Smith SM, Boyd TE, Grant BW, Kolibaba KS, Furman RR, Buggy JJ, Loury DJ, Hedrick E, Izumi R, Hamdy AM, Fowler NH: The Btk Inhibitor Pci-32765 Is Highly Active and Well Tolerated in Patients (Pts) with Relapsed/Refractory B Cell Malignancies: Final Results from a Phase I Study. Annals of Oncology 2011, 22:135-135.

46. Vuyyuru R, Mohan C, Manser T, Rahman ZS: The lupus susceptibility locus Sle1 breaches peripheral B cell tolerance at the antibody-forming cell and germinal center checkpoints. J Immunol 2009, 183:5716-5727.

47. Gutierrez T, Halcomb KE, Coughran AJ, Li QZ, Satterthwaite AB: Separate checkpoints regulate splenic plasma cell accumulation and lgG autoantibody production in Lyn-deficient mice. Eur J Immunol 2010, 40:1897-1905.

48. Kawakami Y, Inagaki N, Salek-Ardakani S, Kitaura J, Tanaka H, Nagao K, Xiao W, Nagai H, Croft M, Kawakami T: Regulation of dendritic cell maturation and function by Bruton's tyrosine kinase via IL-10 and Stat3. Proc Natl Acad Sci USA 2006, 103:153-158.

49. Hata D, Kawakami Y, Inagaki N, Lantz CS, Kitamura T, Khan WN, MaedaYamamoto M, Miura T, Han W, Hartman SE, Yao L, Nagai H, Goldfeld AE, Alt FW, Galli SJ, Witte ON, Kawakami T: Involvement of Bruton's tyrosine kinase in FcepsilonRl-dependent mast cell degranulation and cytokine production. J Exp Med 1998, 187:1235-1247.

50. Heller F, Lindenmeyer MT, Cohen CD, Brandt U, Draganovici D, Fischereder M, Kretzler M, Anders HJ, Sitter T, Mosberger I, Kerjaschki D, Regele H, Schlondorff D, Segerer S: The contribution of B cells to renal interstitial inflammation. Am J Pathol 2007, 170:457-468.

51. Segerer S, Schlondorff D: B cells and tertiary lymphoid organs in renal inflammation. Kidney Int 2008, 73:533-537.

52. Renner B, Strassheim D, Amura CR, Kulik L, Ljubanovic D, Glogowska MJ, Takahashi K, Carroll MC, Holers VM, Thurman JM: B cell subsets contribute to renal injury and renal protection after ischemia/reperfusion. J Immunol 2010, 185:4393-4400

53. Satterthwaite $A B$, Willis $F$, Kanchanastit $P$, Fruman $D$, Cantley $L C$, Helgason CD, Humphries RK, Lowell CA, Simon M, Leitges M, Tarakhovsky A, Tedder TF, Lesche R, Wu H, Witte ON: A sensitized genetic system for the analysis of murine $B$ lymphocyte signal transduction pathways dependent on Bruton's tyrosine kinase. Proc Natl Acad Sci USA 2000, 97:6687-6692.

54. Sasaki Y, Derudder E, Hobeika E, Pelanda R, Reth M, Rajewsky K, SchmidtSupprian M: Canonical NF-kappaB activity, dispensable for B cell development, replaces BAFF-receptor signals and promotes B cell proliferation upon activation. Immunity 2006, 24:729-739.

55. Anderson JS, Teutsch M, Dong Z, Wortis HH: An essential role for Bruton's [corrected] tyrosine kinase in the regulation of B-cell apoptosis. Proc Natl Acad Sci USA 1996, 93:10966-10971.

56. Mangla A, Khare A, Vineeth V, Panday NN, Mukhopadhyay A, Ravindran B, Bal V, George A, Rath S: Pleiotropic consequences of Bruton tyrosine kinase deficiency in myeloid lineages lead to poor inflammatory responses. Blood 2004, 104:1191-1197.

57. Uckun F, Ozer Z, Vassilev A: Bruton's tyrosine kinase prevents activation of the anti-apoptotic transcription factor STAT3 and promotes apoptosis in neoplastic B-cells and B-cell precursors exposed to oxidative stress. $\mathrm{Br}$ J Haematol 2007, 136:574-589.

58. Honda F, Kano H, Kanegane H, Nonoyama S, Kim ES, Lee SK, Takagi M, Mizutani S, Morio T: The kinase Btk negatively regulates the production of reactive oxygen species and stimulation-induced apoptosis in human neutrophils. Nat Immunol 2012, 13:369-378.

doi:10.1186/ar4086

Cite this article as: Hutcheson et al:: Modulating proximal cell signaling by targeting Btk ameliorates humoral autoimmunity and end-organ disease in murine lupus. Arthritis Research \& Therapy 2012 14:R243.

\section{Submit your next manuscript to BioMed Central and take full advantage of:}

- Convenient online submission

- Thorough peer review

- No space constraints or color figure charges

- Immediate publication on acceptance

- Inclusion in PubMed, CAS, Scopus and Google Scholar

- Research which is freely available for redistribution

Submit your manuscript at www.biomedcentral.com/submit 